\title{
Day to day treatment variations of accelerated partial breast brachytherapy using a multi-lumen balloon
}

\author{
Hsiang-Chi Kuo, PhD!, Keyur J. Mehta, MD', Linda Hong, PhD!, Ravindra Yaparpalvi, MS', Leslie L. Montgomery, MD², \\ William Bodner, MD', Wolfgang A. Tomé, PhD', Shalom Kalnicki, MD' \\ 'Department of Radiation Oncology, ${ }^{2}$ Department of Surgery, Montefiore Medical Center; Einstein Institute of Oncophysics, Albert Einstein \\ College of Medicine, Bronx, NY, USA
}

\begin{abstract}
Purpose: To evaluate the variations of multi-lumen balloon (MLB)-based brachytherapy from simulation day to treatment day and their dosimetric impacts during accelerated partial breast irradiation (APBI).

Material and methods: A total of $42 \mathrm{CT}$ images scanned from seven patients were evaluated with regards to daily variation due to of: 1) internal uncertainty: size and shape of balloon, seroma volume; 2) geometrical uncertainty-random: length of each catheter was measured for each fraction (total 70); 3) geometrical uncertainty-systematic: virtual systematic errors were tested by offsetting dwell positions. The original plans (as group A) had a mean value of $96.8 \%$ on $\mathrm{V}_{95}$ of the PTV_Eval. Plans were rerun (as group B) such that the mean value of the $\mathrm{V}_{95}$ was relaxed to $90.4 \%$. By applying the reference plan to each daily CT image, variations of target coverage under different sources of error were evaluated.

Results: Shape and size of the balloon had means of $<1 \mathrm{~mm}$ decreased in diameter and $<0.4 \mathrm{~cm}^{3}$ decreased in volume; the mean seroma volume increased by $0.2 \mathrm{~cm}^{3}$. This internal variation has a mean of $<1 \%$ difference for both $\mathrm{V}_{90}$ and $\mathrm{V}_{95}$. The geometrical uncertainty made a mean deviation of $2.7 \mathrm{~mm}$ per root of sum of square. It caused the degradations of $\mathrm{V}_{90}$ and $\mathrm{V}_{95}$ by mean values of $1.0 \%$ and $1.2 \%$, respectively. A systematic error of $3 \mathrm{~mm}$ and $4 \mathrm{~mm}$ would degrade both of $\mathrm{V}_{90}$ and $\mathrm{V}_{95}$ by $4 \%$ and $6 \%$, respectively. The degradations on target coverage of the plans in group $\mathrm{A}$ were statistically the same as those in group B.

Conclusions: Overall, APBI treatments with MLB based brachytherapy are precise from day to day. However, minor variation due to daily treatment uncertainties can still degrade tumor bed coverage to an unacceptable coverage when $\mathrm{V}_{95}$ of the original plan is close to $90 \%$.
\end{abstract}

J Contemp Brachytherapy 2014; 6, 1: 68-75 DOI: 10.5114/jcb.2014.42025

Key words: APBI, brachytherapy, breast cancer, Contura, multi-lumen balloon, treatment uncertainty.

\section{Purpose}

Studies of local recurrences in patients without adjuvant whole breast irradiation (WBI) demonstrated that the majority of in-breast tumor recurrences are within the tumor bed [1-4]. These results support that APBI (accelerated partial breast irradiation) could be a possible option to deliver adjuvant radiation therapy after lumpectomy in patients undergoing breast-conserving therapy (BCT). Results from phase I/II/III studies have shown acceptable local control and cosmesis with APBI [5-7]. Another socio-economic reason that makes APBI a popular choice is that the accelerated treatment, which is typically completed within a week, offers a convenient choice to patients with restricted access to radiation therapy facilities.
Tangential beam irradiation of the whole breast is the traditional technique used to spare lung dose in WBI. Conversely, APBI needs to spare normal breast tissue as much as possible such that $3 \mathrm{D}$ conformal radiotherapy (3D CRT) instead of the tangential beam arrangement should be applied in external radiation. APBI using brachytherapy (BT) provides an attractive alternative to 3D CRT. APBI uses 3D CRT as well as interstitial multicatheter brachytherapy (IMBT) planned either to cover a $10-15 \mathrm{~mm}$ expansion on the excision cavity plus another $10 \mathrm{~mm}$ PTV margin (3D CRT) or to cover 10-20 mm of the surrounding breast tissue of the lumpectomy cavity. APBI using IMBT has the longest treatment history and has provided the most treatment outcome, which is still the standard in evaluating newer APBI technique. MammoSite ${ }^{\circledR}$ Radiation Therapy System (MS) (Hologic

\footnotetext{
Address for correspondence: Hsiang-Chi Kuo, PhD, Asst. Prof., Department of Radiation Oncology, ～Received: 08.11.2013 Montefiore Medical Center, Albert Einstein College of Medicine, 111 East 210th Street, Bronx, NY 10467, USA, Accepted: 08.03.2014 phone: +1 718-405-8573, fax: +1 718-405-8561, 凶e-mail: hskuo@montefiore.org

Published: 28.03.2014
} 
Inc., Bedford, MA, USA) offers easier intracavitary implementation to the resection cavity by use of a single lumen balloon, and has been demonstrated as a mature APBI technique. The later developed multilumen balloon (MLB) combines the simplified balloon placement with more complex and flexible dosimetry of IMBT technique [8]. The target volume for the balloon based APBI is to $10 \mathrm{~mm}$ (less $5 \mathrm{~mm}$ from skin) surrounding the inflated balloon. Due to a tighter margin, the variations from daily treatment should be closely monitored.

Treatment uncertainties exist at each stage of the radiation therapy process [9]. In general, patient-specific clinical uncertainties are related to interfraction and interfraction movement of both target and adjacent organs at risk (OARs). These uncertainties are easier to analyze with geometrical uncertainties and internal uncertainties in BT [10]. Geometrical uncertainties are related to source positioning and to reconstruction of the applicator [11]. Internal uncertainties are caused by potential displacement of the applicator, relative to the target and/or movement of OARs during BT irradiation or in between imaging and dose delivery $[12,13]$. AAPM has proposed a task group to develop a consensus on a minimum set of initial QA procedures for clinical implementation of 3D CT-based intracavitary breast brachytherapy. The proposed QA procedures (revised February 13, 2012) includes QA for applicator (physical integrity, source-position accuracy on each lumen, and uncertainty of a catheter length) and QA for CT-based treatment planning (physical dimensions of applicator in CT datasets, applicator reconstruction accuracy, verify DVH, and optimal concentration of image contrast medium in the imaging of applicator). This study aimed to investigate the integrity and variation of daily treatment with MLB. By utilizing CT image-guided BT technique in $4 \mathrm{D}$, daily variations of the MLB implementation were analyzed. The dosimetric impact from these variations was also evaluated.

\section{Material and methods}

A total of $42 \mathrm{CT}$ images (one simulation CT plus five daily CTs for each patient) scanned from 7 patients with implanted Contura ${ }^{\circledR}$ Multilumen Ballon (SenoRx, C.R. Bard, Inc., Murray Hill, NJ, USA) were acquired and evaluated in this study. Each patient had at least five $5 \mathrm{~mm}$ titanium clips placed at the medial, lateral, superior, inferior, and deep cavity edge (positioned in the center of the cavity) at the time of breast-conserving surgery. Balloon was implanted using ultrasound with close end technique. Depending on the cavity size, different amount of water and $1.5 \mathrm{~cm}^{3} \sim 2 \mathrm{~cm}^{3}$ of contrast medium was infused into balloon. Each CT acquisition was done using the following procedures: 1) re-position patient with mold by using lasers against medial and lateral markers, which were marked during simulation; 2) check the orientation of the balloon by aligning lumen \#1 with the skin marker drawn during simulation; 3) check the conformance of the balloon to tumor bed by evaluating the air-fluid pocket in CT images; 4) use the vacuum port to aspirate the air-fluid if it is significant and then rescan; 5) measure and record the treatment length of each lumen of the balloon;
6) reconstruct the $1 \mathrm{~mm}$ thickness $\mathrm{CT}$ images to $22 \times 22 \mathrm{~cm}$ field of view (FOV) before exporting CT images to the Oncentra ${ }^{\circledR}$ Planning System (Nucletron, an Elekta company, Stockholm, Sweden) for planning.

After the balloon was contoured in each CT image, a PTV_Eval was created using a $10 \mathrm{~mm}$ expansion from the balloon, then excluding the balloon volume, the chest wall, and $5 \mathrm{~mm}$ from the skin surface. The volume of the $10 \mathrm{~mm}$ expansion from balloon was designated as target volume, where target points were generated on its surface for further dose point optimization. An inner skin surface, which was the $2 \mathrm{~mm}$ inner distance from external surface $[14,15]$, and the rib closest to the balloon were delineated to measure the maximum skin dose, $\left(D_{\text {skin }}\right)$, and maximum dose to rib, $\left(D_{\text {rib }}\right)$, respectively. The maximum dose reported in this study was the $0.1 \mathrm{~cm}^{3}$ of the corresponding volume. Planning goals of the original (reference) plan were $95 \%$ prescription dose (PD) to more than $95 \%$ of the $\mathrm{V}_{\text {PTV_Eval }}$ (PTV_Eval volume) $-\mathrm{V}_{95}>95 \%, \mathrm{D}_{\text {skin }}$ $<125 \%$ PD, $\mathrm{D}_{\text {rib }}<125 \% \mathrm{PD}$, the $\mathrm{V}_{\text {PTV Eval }}$ received $150 \%$ PD $\left(\mathrm{V}_{150}\right)<50 \mathrm{~cm}^{3}$, and the $\mathrm{V}_{\text {PTV_Eval }}$ received $200 \% \mathrm{PD}$ $\left(\mathrm{V}_{200}\right)<10 \mathrm{~cm}^{3}$. A plan with $90 \%$ PD to less than $90 \%$ of the $V_{\text {PTV_Eval }}-V_{90}<90 \%$ was considered unacceptable. The plan was created using dose point optimization in a volume model and followed by manually adjusting the isodose lines (graphic optimization) to achieve the planning goals. In dose point optimization, each point dose is calculated based on TG-43 with anisotropic correction; the dwell time to each source position is the analytical solution solved with singular value decomposition (SVD) such that each point receives the reference dose (3.4 Gy/ fraction). By interactively updating dose distribution in $3 \mathrm{D}$ and $\mathrm{DVH}$, the graphic optimization allows altering the dwell time weights by locally dragging the isodose lines to adjust the hotspot in the organ at risk and cold spot in target, until the best DHV coverage of PTV_Eval is reached without jeopardizing the other planning goals. This two-step optimization (dose point optimization followed by graphic optimization) has been tested and compared with another IPSA (inverse planning with simulated annealing) optimizations $[16,17]$. Since the results from IPSA were not optimum and needed further graphical adjustment to the iso-dose line, we decided to stay with dose optimization in 3D model for APBI brachytherapy with MLD.

The approved plan generated from the simulation CT (reference CT) was saved as reference plan. The treatment length of the MLB measured on the simulation date was recorded as reference length. Before the AM fraction of each treatment day, the entire CT acquisition above (1-5) was repeated. Before the PM fraction of each treatment, procedures $(1,2,5)$ were repeated without CT scan. There were total $42 \mathrm{CT}$ image sets acquired (includes 7 sets form simulation) and 77 treatment lengths recorded (includes 7 reference lengths).

\section{Evaluation of variations due to internal uncertainties (INT $\left.T_{R}\right)$}

In each CT image set, balloon size $\left(\mathrm{V}_{\text {balloon }}\right)$, diameters of the balloon in $\mathrm{AP}$, and Lat directions $\left(\mathrm{d}_{\mathrm{AP}}, \mathrm{d}_{\text {Lat }}\right)$, 
the closest skin-to-balloon distance $\left(\mathrm{d}_{\text {skin }}\right)$, the closest balloon-to-rib distance $\left(\mathrm{d}_{\text {rib }}\right)$, and the volume of air-fluid pocket $\left(\mathrm{V}_{\text {seroma }}\right)$, were measured and recorded. Daily internal variations were measured by comparing the differences between the $V_{\text {balloon }}, d_{A P}, d_{\text {Lat }}, d_{\text {skin }}, d_{\text {rib }}$, and $V_{\text {seroma }}$ in daily $\mathrm{CT}$ image with those in simulation $\mathrm{CT}$ image in terms of $\Delta \mathrm{V}_{\text {balloon }}, \Delta \mathrm{d}_{\mathrm{AP}}, \Delta \mathrm{d}_{\text {Lat }}, \Delta \mathrm{d}_{\text {skin }}, \Delta \mathrm{d}_{\text {rib }}$, and $\Delta \mathrm{V}_{\text {seroma }}$ respectively. Conformance of balloon to the resection cavity was ensured, as long as $\mathrm{V}_{\text {seroma }}<2 \%$ or $2 \mathrm{~cm}^{3}$ of the PTV_Eval volume ( $\left.\mathrm{V}_{\text {PTV_Eval }}\right)$. Its impact to $\mathrm{V}_{95}$ and $\mathrm{V}_{90}$ was accounted by subtracting its volume (in \% of $\mathrm{V}_{\text {PTV Eval }}$ if more than $0.5 \mathrm{~cm}^{3}$ ) from the $V_{95}$ and $V_{90}$.

\section{Evaluation of variations due to geometrical uncertainties $\left(G E O_{R} \& G E O_{S}\right)$}

Due to the variations of the patient positions and the measured conditions between treatments, the reading of separate measured treatment lengths could be different. Each catheter length was measured and recorded for each fraction (total of 70 fractions). Since there are five lumens in a Contura (SenoRx, C.R. Bard, Inc., USA) balloon, the deviation of the catheter length in each fraction is reported by the root of sum of square:

$$
\mathrm{RSQ}_{\mathrm{L}}=\sqrt{\sum_{i=1}^{5} \Delta l_{\mathrm{i}}^{2}}
$$

where $\Delta l_{i}$ is the deviation of the length of catheter " $\mathrm{i}$ " from its first measured length. By repopulating the time weight of each dwell position of the reference plan onto the corresponding dwell position reconstructed from each daily CT image, dose variations to PTV_Eval, tumor bed (surgical clips), skin, and rib were evaluated with and without daily catheter length corrections. The deviation of the catheter length from the first measurement during simulation was corrected by rounding to the nearest millimeter then offsetting the dwell positions of the corresponding catheter in CT image acquired from treatment day. The variation of catheter length measured from day to day was considered as random variation. The impact of the systematic errors related to source poisoning, treatment length measuring tool, and reconstruction of the catheters in planning system were accounted and tested by systematically offsetting the en- tire dwell positions of each catheter with $\pm 1 \mathrm{~mm}, \pm 2 \mathrm{~mm}$, $\pm 3 \mathrm{~mm}$, and $\pm 4 \mathrm{~mm}$.

\section{Evaluated parameters}

Dosimetric impact was measured in terms of $\Delta \mathrm{V}_{90}$, $\Delta \mathrm{V}_{95}, \Delta \mathrm{V}_{150}$, and $\Delta \mathrm{V}_{200}$. Dose change in each surgical clip was measured as the minimum dose received by $50 \%$ volume of the contoured surgical clip. Dose deviation was compared with and without daily treatment length corrections. $\Delta \mathrm{V}_{95}$ and $\Delta \mathrm{V}_{90}$ were compared with different type of variations, include daily internal variation from CT image only $\left(\mathrm{INT}_{\mathrm{R}}\right)$, plus daily treatment length variation $\left(G E O_{R}\right)$, or plus systematic error with different entire treatment shift $\left(\mathrm{GEO}_{\mathrm{S}}\right)$. Both of $\mathrm{GEO}_{\mathrm{R}}$ and $\mathrm{GEO}_{\mathrm{S}}$ were measured from treatment $\mathrm{CT}$, the results inherently included the effect of $\mathrm{INT}_{\mathrm{R}}$.

\section{Relaxed plan and statistical analysis}

To simulate the dosimetric impact of the plans that did not meet planning goals due to too small skin distance (e.g., $\mathrm{d}_{\text {skin }}<5 \mathrm{~mm}$ ), each plan was relaxed to $\mathrm{V}_{95}=90 \%$ by graphically dragging the iso-dose line of the original plan inner away from breast tissue. The results from the original plans were grouped as A and the results from the relaxed plans were grouped as B. Dosimetric impact due to daily variations on MLB was compared between group $\mathrm{A}$ and group $\mathrm{B}$ by two-sided paired sample $t$-test on the parameters of $\Delta \mathrm{V}_{95}, \Delta \mathrm{V}_{90}, \Delta \mathrm{V}_{150}$, and $\Delta \mathrm{V}_{200}$. It is considered a significant difference when $p$ value $<0.05$.

\section{Results}

\section{Internal variations $\left(\mathrm{INT}_{R}\right)$}

Table 1 lists the initial anatomic parameters from the simulation CT image set and its corresponding plan evaluated parameters. Comparing 7 simulation $\mathrm{CT}$ image sets with 35 daily treatment CT image sets, $\mathrm{d}_{\mathrm{AP}}$ and $\mathrm{d}_{\text {Lat }}$ of the balloon, which had initial mean values of $40.9 \mathrm{~mm}$ AP and $45.4 \mathrm{~mm}$ Lat, had a mean decrease of $0.9 \mathrm{~mm}$ and $0.2 \mathrm{~mm}$, respectively; $\mathrm{V}_{\text {balloon' }}$ which had an initial mean value of $41.8 \mathrm{~cm}^{3}$, had a mean decrease of $0.4 \mathrm{~cm}^{3} ; \mathrm{V}_{\text {seroma }}$ which had an initial mean value of $0.2 \mathrm{~cm}^{3}$, had a mean

Table 1. Summary of the initial anatomic parameters from the reference CT image set and its corresponding plan evaluated parameters (group A) for each patient in this study. Values within the parenthesis were plan parameters for group $B$

\begin{tabular}{lcccccccccc} 
Patient & $\mathrm{d}_{\text {AP }}{ }^{1}$ & $\mathrm{~d}_{\text {Lat }}{ }^{1}$ & $\mathrm{~V}_{\text {balloon }}{ }^{2}$ & $\mathrm{~V}_{\text {PTV_Eval }}{ }^{2}$ & $\mathrm{~V}_{\text {seroma }}{ }^{2}$ & $\mathrm{~d}_{\text {skin }}{ }^{1}$ & $\mathrm{~d}_{\text {rib }}{ }^{1}$ & $\mathrm{~V}_{95}{ }^{3}$ & $\mathrm{D}_{\text {skin }}{ }^{3}$ & $\mathrm{D}_{\text {rib }}{ }^{3}$ \\
\hline 1 & 51 & 53 & 69.4 & 120.2 & $<0.1$ & 14 & 24 & $100(90.9)$ & $80.7(74.9)$ & $55.8(47.6)$ \\
\hline 2 & 35 & 40 & 27.3 & 75.6 & $<0.1$ & 14.6 & 16.4 & $99.5(90.1)$ & $75.5(68)$ & $61.4(57.1)$ \\
\hline 4 & 38 & 43 & 31.1 & 79.7 & 0.1 & 33 & 15 & $97.9(90.5)$ & $29.0(27.4)$ & $63.1(39.8)$ \\
\hline 5 & 42 & 55 & 48.3 & 101.5 & $<0.1$ & 22 & 4 & $95.0(90.6)$ & $55.4(52.2)$ & $116.3(108.1)$ \\
\hline 6 & 42 & 41 & 37.3 & 87.2 & $<0.1$ & 13 & 38 & $97.7(90.3)$ & $97.6(88.5)$ & $29.7(27.8)$ \\
\hline Mean & 45 & 50 & 55.1 & 107.1 & $<0.1$ & 12 & 5 & $95.1(90.0)$ & $101.4(95.0)$ & $121.9(117.8)$ \\
\hline & 33 & 36 & 24 & 65 & 1.1 & 21 & 4 & $92.4(90.1)$ & $61.6(61.1)$ & $122.4(117.3)$ \\
\hline
\end{tabular}

Unit: ${ }^{1}-m m ;^{2}-c m^{3} ;{ }^{3}-\%$. 
increase of $0.2 \mathrm{~cm}^{3} ; \mathrm{d}_{\text {skin }}$ and $\mathrm{d}_{\text {rib, }}$, which had an initial mean values of $18.5 \mathrm{~mm}$ and $15.2 \mathrm{~mm}$, had a mean decrease of $1.3 \mathrm{~mm}$ and a mean increase of $3.1 \mathrm{~mm}$, respectively. A larger variation of daily reading from the initial reading within patient's treatments and between patient's treatments was seen in $d_{\text {skin. }}$. The variation of $d_{\text {skin }}$ from day to day for each patient and its corresponding dosimetric impact due to the variation were illustrated in Figure 1. The changes of the relationship between balloon and anatomy making $\mathrm{V}_{\text {PTV_Eval, }}$ which had an initial mean value $90.9 \mathrm{~cm}^{3}$, had a mean decrease of $1.7 \mathrm{~cm}^{3}$. The overall dosimetric impact of these internal variations had a minor impact on $\Delta \mathrm{V}_{90}, \Delta \mathrm{V}_{95}, \Delta \mathrm{V}_{150}$, and $\Delta \mathrm{V}_{200}$ with mean values of $-0.3 \%, 0.1 \%, 0.8 \mathrm{~cm}^{3}$ and $0.7 \mathrm{~cm}^{3}$, respectively.

\section{Geometrical variations $\left(G E O_{R} \& G E O_{S}\right)$}

In addition to $\mathrm{INT}_{\mathrm{R}}$, Table 2 demonstrates the dosimetric impact of $\mathrm{GEO}_{\mathrm{R}}$ and $\mathrm{GEO}_{\mathrm{S}}$ on PTV_Eval. The variation of the treatment lengths of the five lumens in terms of $\mathrm{RSQ}_{\mathrm{L}}$ had a mean value of $2.7 \mathrm{~mm}$. On top of $\mathrm{INT}_{\mathrm{R}}$ this deviation caused further degradation of the PTV_Eval coverage and an increase of the hot spot within PTV_Eval for both of group $\mathrm{A}$ and group $\mathrm{B}$. There were mean values of $-1 \%,-1.2 \%, 0.8 \mathrm{~cm}^{3}$, and $1.0 \mathrm{~cm}^{3}$ for $\Delta \mathrm{V}_{90}, \Delta \mathrm{V}_{95}, \Delta \mathrm{V}_{150}$ and $\Delta V_{200}$ of group $A$, respectively. The impacts of $\mathrm{INT}_{\mathrm{R}} \&$ $\mathrm{GEO}_{\mathrm{R}}$ on the mean dose (which is close to $50 \%$ DVH value) of each surgical clip are displayed in Figure 2. Although the statistical normality test did not suggest the frequency distributions follow a normal distribution, which may be due to too small of a sample set, both distributions showed the impacts were random.

The lower half of Table 2 summarizes the degradation of the PTV_Eval coverage related to $\mathrm{GEO}_{\mathrm{S}}$ (on top of $\mathrm{INT}_{\mathrm{R}}$ ). In terms of $\Delta \mathrm{V}_{90}$ for group $\mathrm{A}$, they were $-0.0 \%$ and $-0.7 \%$ for $\pm 1 \mathrm{~mm},-0.7 \%$ and $-1.9 \%$ for $\pm 2 \mathrm{~mm},-2.1 \%$ and $-3.6 \%$ for $\pm 3 \mathrm{~mm}$, and $-4 \%$ and $-5.6 \%$ for $\pm 4 \mathrm{~mm}$. In terms of $\Delta \mathrm{V}_{95}$ for group $\mathrm{A}$, they were $-0.0 \%$ and $-0.8 \%$ for \pm $1 \mathrm{~mm},-1.1 \%$ and $-2.4 \%$ for $\pm 2 \mathrm{~mm},-2.8 \%$ and $-4.4 \%$ for \pm $3 \mathrm{~mm}$, and $-5.2 \%$ and $-6.7 \%$ for $\pm 4 \mathrm{~mm}$. The values of $\Delta \mathrm{V}_{90}$ and $\Delta \mathrm{V}_{95}$ in group $\mathrm{B}$ had similar mean and variance compared to those in group B.

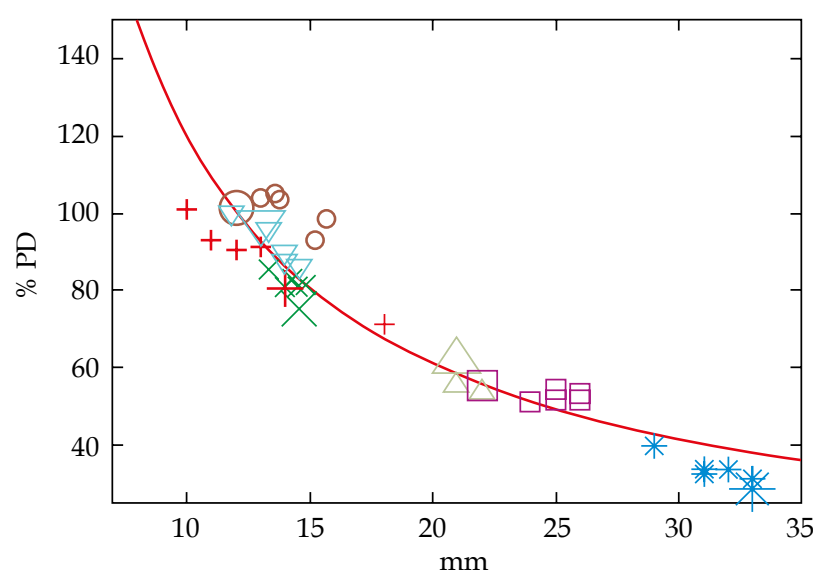

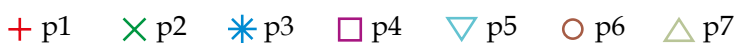

Fig. 1. Scatterplot of the variation of $d_{\text {skin }}$ due to $I N T_{R}$ and the corresponding $\mathrm{D}_{\text {skin, }}$ where “\% PD" was the percentage of the prescription dose and the larger symbols were the intial values taken from reference CT

\section{Relaxed plan and statistical analysis}

Comparing original plans in group $\mathrm{A}$, which has a mean $\mathrm{V}_{95}$ of $96.8 \%$, and the relaxed plans in group $\mathrm{B}$, which has a mean $\mathrm{V}_{95}$ of $90.4 \%$, using the testing parameters $\mathrm{INT}_{\mathrm{R}}, \mathrm{GEO}_{\mathrm{R}}$ and $\mathrm{GEO}_{\mathrm{S}}( \pm 1 \mathrm{~mm}, \pm 2 \mathrm{~mm}, \pm 3 \mathrm{~mm}$, and $\pm 4 \mathrm{~mm}$ ), the $p$ values (median and range) for $\Delta \mathrm{V}_{90}, \Delta \mathrm{V}_{95}$, $\Delta \mathrm{V}_{150}$, and $\Delta \mathrm{V}_{200}$ were $0.25[0.04,0.64], 0.58$ [0.10, 0.93], $0.04[0.01,0.28]$, and $0.29[0.23,0.94]$, respectively. It indicated that only $\Delta \mathrm{V}_{150}$ (on $\mathrm{GEO}_{\mathrm{S}}$ with $\pm 2 \mathrm{~mm}, \pm 3 \mathrm{~mm}$, and $\pm 4 \mathrm{~mm}$ ) showed a significant difference between these two groups. Since the majority of differences were not significant, the statistics display shown in Figure 3 were evaluated including both groups. It showed that the $\mathrm{INT}_{R}$ had the least dosimetric impact, followed by $\mathrm{GEO}_{\mathrm{S}-1 \mathrm{~mm}}$, $\mathrm{GEO}_{\mathrm{R}}, \mathrm{GEO}_{\mathrm{S}-2 \mathrm{~mm}}, \mathrm{GEO}_{\mathrm{S}-3 \mathrm{~mm}}$, and $\mathrm{GEO}_{\mathrm{S}-4 \mathrm{~mm}}$. In terms of the percentage of plans that became unacceptable plans

Table 2. Summary of internal variations due to the change of balloon and anatomy, geometrical variations due to the change of catheter length, size of systematic error, and their dosimetric impact on PTV_Eval

\begin{tabular}{|c|c|c|c|c|c|c|c|c|c|c|c|}
\hline & $\Delta d_{A P}^{1}$ & $\Delta \mathrm{d}_{\text {Lat }}^{1}$ & $\Delta \mathrm{V}_{\text {balloon }}{ }^{2}$ & $\Delta \mathrm{V}_{\text {seroma }}{ }^{2}$ & $\Delta \mathrm{d}_{\text {skin }}{ }^{1}$ & $\Delta \mathrm{d}_{\mathrm{rib}}{ }^{1}$ & $\Delta \mathrm{V}_{90}{ }^{3}$ & $\Delta \mathrm{V}_{95}^{3}$ & $\Delta \mathrm{V}_{150^{2}}$ & $\Delta \mathrm{V}_{200^{2}}$ & $\mathrm{RSQ}_{\mathrm{L}}{ }^{3}$ \\
\hline${ }^{*} \mid N T_{R}$ & $-0.9 \pm 2.1$ & $-0.2 \pm 1.1$ & $-0.4 \pm 1.6$ & $0.2 \pm 0.9$ & $-1.4 \pm 9.6$ & $3.1 \pm 7.0$ & $-0.3 \pm 2$ & $0.1 \pm 2$ & $0.8 \pm 2.7$ & $0.7 \pm 2$ & \\
\hline SINT $R$ & & & & & & & $-0.3 \pm 2$ & $0.0 \pm 2$ & $0.8 \pm 2.7$ & $0.7 \pm 2$ & \\
\hline${ }^{*} \mathrm{GEO}_{\mathrm{R}}$ & & & & & & & $-1.6 \pm 2$ & $-1.2 \pm 2$ & $0.8 \pm 2.7$ & $1.0 \pm 2.8$ & $2.7 \pm 1.6$ \\
\hline${ }^{\$} \mathrm{GEO}_{\mathrm{R}}$ & & & & & & & $-1.0 \pm 2$ & $-1.3 \pm 2$ & $0.7 \pm 2.8$ & $1.0 \pm 3$ & \\
\hline $\mathrm{GEO}_{\mathrm{S}}$ & $\mathrm{S}_{-4 \mathrm{~mm}}$ & $\mathrm{~S}_{-3 \mathrm{~mm}}$ & $\mathrm{~S}_{-2 \mathrm{~mm}}$ & $\mathrm{~S}_{-1 \mathrm{~mm}}$ & $\mathrm{~S}_{1 \mathrm{~mm}}$ & $\mathrm{~S}_{2 \mathrm{~mm}}$ & $\mathrm{~S}_{3 \mathrm{~mm}}$ & $\mathrm{~S}_{4 \mathrm{~mm}}$ & & & \\
\hline${ }^{*} \Delta \mathrm{V}_{90}{ }^{1}$ & $-4.0 \pm 8$ & $-2.1 \pm 6$ & $-0.7 \pm 4$ & $-0.0 \pm 2$ & $-0.7 \pm 2$ & $-1.9 \pm 3$ & $-3.6 \pm 5$ & $-5.6 \pm 7$ & & & \\
\hline$\$ \Delta V_{90}{ }^{1}$ & $-5.6 \pm 13$ & $-3.4 \pm 11$ & $-1.6 \pm 8$ & $-0.5 \pm 4$ & $-0.9 \pm 4$ & $-2.6 \pm 7$ & $-4.9 \pm 7$ & $-7.7 \pm 8$ & & & \\
\hline${ }^{*} \Delta \mathrm{V}_{95}{ }^{1}$ & $-5.2 \pm 11$ & $-2.8 \pm 9$ & $-1.1 \pm 7$ & $0.0 \pm 4$ & $-0.8 \pm 3$ & $-2.4 \pm 5$ & $-4.4 \pm 7$ & $6.7 \pm 9$ & & & \\
\hline${ }^{\$} \Delta \mathrm{V}_{95}{ }^{1}$ & $-4.4 \pm 13$ & $-2.1 \pm 11$ & $-0.5 \pm 8$ & $0.5 \pm 5$ & $0.0 \pm 4$ & $-1.6 \pm 7$ & $-4.0 \pm 8$ & $-6.8 \pm 8$ & & & \\
\hline
\end{tabular}

Unit: ${ }^{1}, \mathrm{~mm} ;{ }^{2}, \mathrm{~cm}^{3} ;{ }^{3}, \%$. Value displays as Mean $\pm 2 S D$. "*”: Group A; "\$”: Group B. 


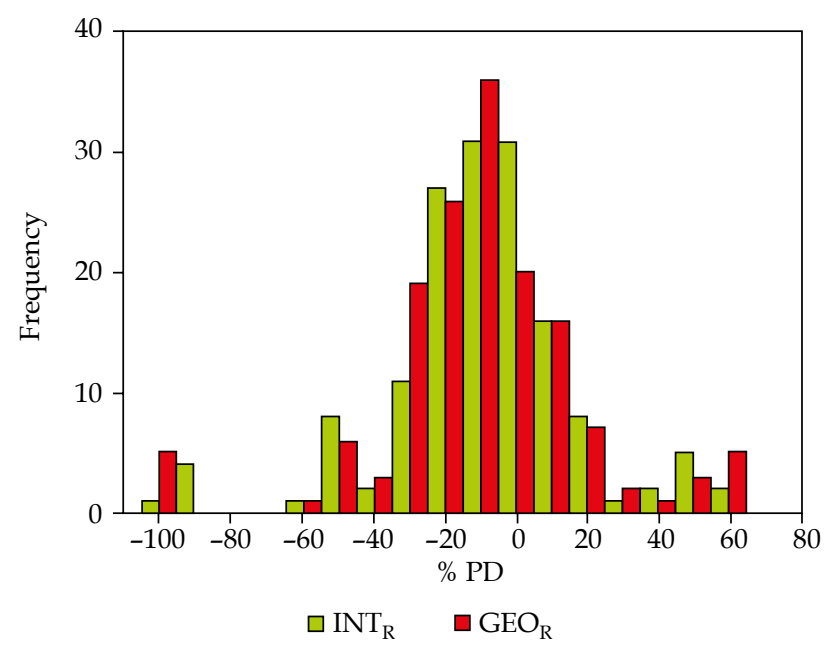

Fig. 2. Frequency distribution of the change of $50 \%$ dose of sugical clips due to $\mathrm{INT}_{\mathrm{R}}$ and $\mathrm{GEO}_{\mathrm{R}}$, in terms of the percentage of priscription dose

$\left(\mathrm{V}_{90}<90 \%\right)$ due to daily treatment variations in this study, in group $\mathrm{A}$, the chance was less than $3 \%$, even if there was a $3 \mathrm{~mm}$ systemetic error since its baseline (mean $\mathrm{V}_{95}=$ $96.8 \%$ ) was high. However, in group B, the chance was more than $14 \%$ and $34 \%$ if the systematic error was more than $2 \mathrm{~mm}$ and $3 \mathrm{~mm}$, respectively.

\section{Discussion}

In an effort to analyze the day to day variation of APBI in patients implanted with MLB, this study used daily $\mathrm{CT}$ and pre-treatment catheter length measurements to demonstrate the possible variations due to internal vari-
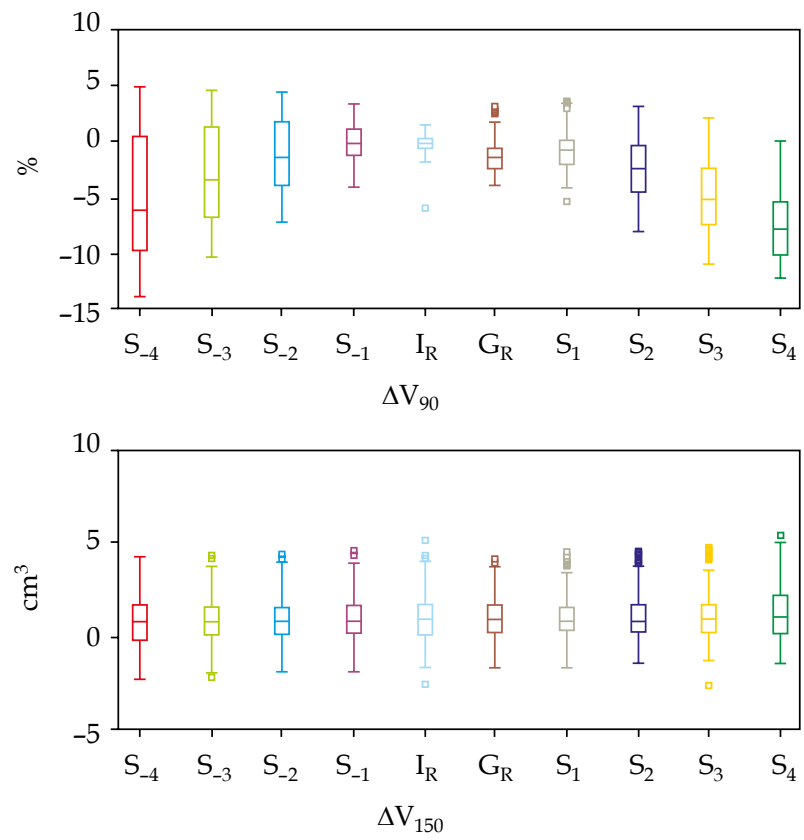

ation and geometrical uncertainties. The major variations of an intracavitary balloon implant include the conformance of the balloon to the resection cavity, shape of the balloon, distance of balloon to OARs, and edema of the breast tissue around the tumor bed due to the implant. It has been reported that a high percentage of implanted patients had balloons explanted due to poor cavity-balloon conformance, or inadequate skin spacing $[18,19]$. Contu$\mathrm{ra}^{\circledR}$ (SenoRx, C.R. Bard, Inc., USA) MLB has a vacuum port, which can be used to aspirate the air-fluid pocket if it is significant. Studies have shown that some patients are likely to produce seroma after surgery or implantation [20]. Bhatt [21] observed a trend for larger seroma accumulation if the volume drawn on the first day of treatment was more than $3-6 \mathrm{~cm}^{3}$, comparing to those of $0-2 \mathrm{~cm}^{3}$. Their data suggested that serial aspiration may benefit a subpopulation of patients in terms of tissue conformality and reproducibility. Two out of seven patients in this study needed to aspirate the air-fluid pocket a couple of times in five treatment days. After aspiration, only in one CT image the air-fluid pocket had volume slightly more than $2 \mathrm{~cm}^{3}$, which is less than 3\% of the PTV_Eval volume. The variation of the balloon in terms of shape (diameters) and size (volume) were all small. $\mathrm{d}_{\text {skin }}$ was $1.4 \mathrm{~mm}$ smaller and $\mathrm{d}_{\text {rib }}$ was $3 \mathrm{~mm}$ larger than the distances measured in the reference CT. Edema due to implant of the balloon is difficult to identify with a CT image. With the trend of the increasing $\mathrm{d}_{\text {rib }}$ over time, it could be an indication of the release of the edema.

Dosimetric impact due to MLB rotation has recently studied by Kim et al. [22]. For a plan with both of skin and rib distance smaller than $7 \mathrm{~mm}$, the maximum degradation on $\mathrm{D}_{95}$ of the PTV_Eavl was about $6.5 \%$ when there was a $120^{\circ}$ rotation error. They found that in a clinical situation, which had a rotation error smaller than $10^{\circ}$, the
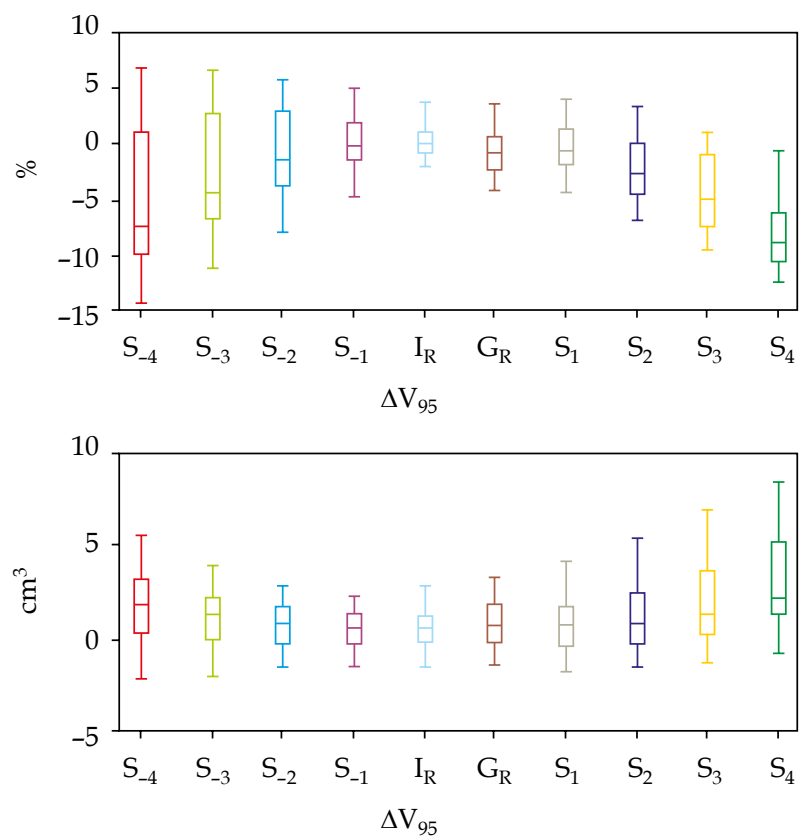

Fig. 3. Boxplots of the dosimetric impacts $\left(\Delta \mathrm{V}_{90}, \Delta \mathrm{V}_{95}, \Delta \mathrm{V}_{150}, \Delta \mathrm{V}_{200}\right)$ vs. different type of variations, where INT is INT $\mathrm{R}^{\prime}$ GEO is $\mathrm{GEO}_{\mathrm{R}}, \mathrm{S}$ represents $\mathrm{GEO}_{\mathrm{S}}$ and is followed with different size of systematic errors 
degradation on $\mathrm{D}_{95}$ and $\mathrm{D}_{90}$ of the PTV_Eval were less than $1 \%$; the deviation of the skin and rib dose were less than $2.5 \%$ of the prescription dose. The geometrical variation due to the orientation of the MLB within the cavity of the lumpectomy had been implicitly evaluated within the $\mathrm{CT}$ image. It was first visually inspected by aligning the line on the shaft of Contura (SenoRx, C.R. Bard, Inc.) with the line drawn on patient at the time of initial CT. Ouhib [23] confirmed that visual inspection with marker alignment is an effective way of verifying the orientation of the MLB before treatment. Our experiences showed that with the shaft of the balloon aligned to the external marker, it should still have minor misalignment internally compared to initial CT image, since both of the shaft of Contura and breast tissue are non-rigid. Including this deviated balloon orientation with the other internal uncertainties between balloon and internal anatomy, the $\mathrm{INT}_{\mathrm{R}}$ in our study showed minimal deviation from the initial plan whether comparing the impact on the tumor bed surrogate, the surgical clips, or directly on the PTV_Eval. The spatial variation of the surgical clips over treatment course has been presented and will be reported separately.

A $2.7 \mathrm{~mm} \mathrm{RSQ}_{\mathrm{L}}$ was not small if compared to the $2 \mathrm{~mm}$ source position tolerance implemented in most HDR QA programs. The cause of the $3 \mathrm{~mm}$ length deviation is not clear. We have observed that the bending and rotation of the middle soft flexible tube caused variations in lumen length. The length could have a deviation of up to $4 \mathrm{~mm}$ if the balloon was rotated by $90^{\circ}$ and the lumen bent by $60^{\circ}$ at the same time. Fortunately, the directions and magnitudes of the deviation varied between the five lumens and usually had an arithmetical mean of less than $1.5 \mathrm{~mm}$. By comparing the overall effect of this $\mathrm{GEO}_{\mathrm{R}}$ with $\mathrm{GEO}_{\mathrm{S}}$ in Figure 3, the mean 1\% degradation of the PTV coverage due to $\mathrm{GEO}_{\mathrm{R}}$ was close to $\mathrm{GEO}_{\mathrm{S}}$ of $\sim 1.5 \mathrm{~mm}$. The dosimetric impact caused by $\mathrm{GEO}_{\mathrm{R}}$ was slightly worse than the impact of $\mathrm{INT}_{\mathrm{R}}$, however, the range of the error induced was tolerable in this study. In contrast, $\mathrm{GEO}_{\mathrm{S}}$ had a larger dosimetric impact compared to $\mathrm{INT}_{\mathrm{R}}$ and $\mathrm{GEO}_{\mathrm{R}}$. The impact increased with the systematic error and the probability that the original plan became unacceptable was proportional to the size of the error. If there were a systematic error of $3 \mathrm{~mm}$, the mean degradation of V95 was $\sim 4 \%$, which would make the majority of the plans in group A became minor deviation from the planning goal and turn more than $30 \%$ of the plans in group B into unacceptable plans.

The geometrical uncertainties analyzed in this study were applied to a PTV volume with a standard $10 \mathrm{~mm}$ margin from the implanted balloon, which was estimated to be equivalent to treatment thickness of $16 \mathrm{~mm}$ and $20 \mathrm{~mm}$ in Dickler and Weed's studies, respectively [24,25]. In a different study [26], Vicini et al. concluded that the effective volume expanded from the $10 \mathrm{~mm}$ MammoSite CTV margin was significantly smaller than the 3D-CRT CTV based on a $15 \mathrm{~mm}$ margin. Besides, definition of the PTV volume was done irrespective to the status of the surgical margin. Studies showed that the majority of the patterns of failure after APBI were out of field recurrence or elsewhere recurrence [27-30]. However, it was confirmed that close-margin or close/positive-margin have a significant increase in IBTR (in breast tumor recurrence) compared to negative-margin [31]. According to the statistics measured by Husain [27], the number of BT cases increased nearly 10-fold from 2002 to 2007, and more than $60 \%$ of the patients who received APBI via BT would fall into ASTRO's cautionary or unsuitable groupings. There is no direct relationship between the patterns of failure and planning coverage, however, it is good practice to plan with objective to meet the goal of $\mathrm{V}_{95}>95 \%$, and to follow a proper QA procedure for a balloon-based APBI patient who is defined as a cautionary or unsuitable APBI BT patient by ASTRO.

This study did not intent to evaluate the variation due to the delineation of the balloon and critical structures, however, efforts have been done to reduce the variation. Each balloon has been infused with about $2 \mathrm{~cm}^{3}$ contrast to increase the visibility of the balloon. Each CT was scanned with $1 \mathrm{~mm}$ thickness and reconstructed with $22 \mathrm{~cm} \times 22 \mathrm{~cm}$ field of view to increase the resolution of the CT image. Albeit, a small number of patients, this study increased the sample size by relaxing plans with $5 \%$ lower than planning goal such that both groups can be tested via day to day uncertainties. As well as small sample size, another limitation of this study is that the impact of day-to-day variations on $\mathrm{D}_{\text {skin }}$ and $\mathrm{D}_{\text {rib }}$ was not intensively studied and documented, since both of $d_{\text {skin }}$ and $d_{\text {rib }}$ in our study were not short enough to receive more than $125 \%$ PD after uncertainties were applied. This preliminary study showed that $d_{\text {rib }}$ tended to be increased from the initial value while $d_{\text {skin }}$ did not have similar trend. The fitting curve in Figure 1 indicated that small initial $\mathrm{d}_{\text {skin }}$ had higher dosimetric impact than large initial $\mathrm{d}_{\text {skin. }}$. A mean decrease of $2 \mathrm{~mm} \mathrm{~d}_{\text {skin }}$ from the reference CT image could have a $20 \% \sim 40 \%$ dose increase in treatment CT image when the initial $d_{\text {skin }}$ is smaller than $12 \mathrm{~mm}$. This would greatly increase the risk of skin complication if the initial $D_{\text {skin }}$ were close to $125 \%$ of the prescription dose. This study did not include case with $d_{\text {skin }}$ smaller than $10 \mathrm{~mm}$. A further study for cases with short skin distance and rib distance is warranted. Although plans were created using a Contura ${ }^{\circledR}$ (SenoRx, C.R. Bard, Inc.) MLB implant, the conclusions can be applied to any balloon based implant including MS (Hologic Inc.). MS (Hologic Inc.) does not need to consider balloon orientation, however, there is no vacuum port, so the volume of the air-fluid pocket has to be monitored. Clinical outcomes of MS (Hologic Inc.) treatments have shown similar recurrence rates to IMBT, but the late toxicity of MS (Hologic Inc.) treatments were much higher than those of IMBT treatments [31]. MLB have no shortcomings in MS (Hologic Inc.) and have the advantages of both MS (Hologic Inc.) and IMBT, making MLB much more applicable than MS (Hologic Inc.) for APBI. However, the treatment history of MLB is still short and it takes 2-5 years for the incidence of recurrence and late toxicity. APBI with MLB needs to be implemented with great care.

It is the purpose of this study to have more understanding on the variation from MLB such that a proper 
QA procedure can be followed. Based on the results of this study, we suggest: 1) setup position should be reproduced and MLB orientation should be checked at each fraction; 2) the measured condition applied to MLB should be as close as possible to the MLB status during treatment with minimal bending and twisting of the MLB; 3 ) the reference treatment lengths measured during simulation should be confirmed at least before the first treatment; 4) ultrasound or CT scan should be checked at least at the first fraction to confirm the integrity of the implanted balloon and no new major air-fluid formation; 5) if serious air-fluid were found, use vacuum port to aspirate the air-fluid; a CT scan needs to be repeated in the following day until no new air-fluid is formed; 6) if air-fluid cannot be eliminated and is more than 5\% of VPTV_Eval, re-plan with new CT or explant the balloon if new plan is not acceptable.

\section{Conclusions}

For MLB-based APBI patients whose treatment positions are reproducible, the day to day variation on balloon size, skin distance, and rib distance has very minimal impact on $\mathrm{V}_{90}, \mathrm{~V}_{95}, \mathrm{~V}_{150}$, and $\mathrm{V}_{200}$. Deviation of measured catheter length from the first day measurement had a mean $\mathrm{RSQ}_{\mathrm{L}}$ of $2.7 \mathrm{~mm}$. Combining the measured deviation of catheter length and the variation from the internal position, $\mathrm{V}_{95}$ was degraded by $-1.2 \pm 2.3 \%$. If there were a systematic error of $3 \mathrm{~mm}$, the mean degradation of $\mathrm{V}_{95}$ was about $4 \%$. It would turn the majority of plans, which has no deviation from the goal of $\mathrm{V}_{95}>95 \%$ into minor deviation of $90 \%<\mathrm{V}_{95}<95 \%$, and turn more than $30 \%$ of the plans with original $\mathrm{V}_{95}$ close to $90 \%$ into an unacceptable plan of $\mathrm{V}_{90}<90 \%$. A proper work flow is essential for MLB-based APBI treatment. A $2 \mathrm{~mm}$ tolerance of a HDR QA program is reasonable for regular MLB implant technique for plans with no or minor deviation from the planning goals. Plans with major deviation (e.g. $\mathrm{V}_{95}<90 \%$ ) should consider to re-implant with different size of balloon or to treat patient with other technique.

\section{Disclosure}

Authors report no conflict of interest.

\section{References}

1. Clark RM, McCulloch PB, Levine MN et al. Randomized clinical trial to assess the effectiveness of breast irradiation following lumpectomy and axillary dissection for node-negative breast cancer. J Natl Cancer Inst 1992; 84: 683-689.

2. Fisher ER, Anderson S, Redmond $C$ et al. Ipsilateral breast tumor recurrence and survival following lumpectomy and irradiation: Pathological findings from NSABP protocol B-06. Semin Surg Oncol 1992; 8: 161-166.

3. Liljeren G, Holmberg L, Bergh J et al. 10-yr results after sector resection with or without postoperative radiotherapy for stage I breast cancer: A randomized trial. J Clin Oncol 1999; 17: 2326-2333.

4. Veronesi U, Marubini E, Mariani L et al. Radiotherapy after breast-conserving surgery in small breast carcinoma: long-term results of a randomized trial. Ann Oncol 2001; 12: 997-1003.

5. Kuske RR, Winter K, Arthur DW et al. Phase II trial of brachytherapy along after lumpectomy for select breast cancer: toxicity analysis of RTOG 95-17. Int J Radiat Oncol Biol Phys 2006; 65: 45-51.

6. Arthur DW, Winter K, Kuske RR et al. Phase II trial of brachytherapy along after lumpectomy for select breast cancer: tumor control and survival outcomes of RTOG 95-17. Int J Radiat Oncol Biol Phys 2008; 72: 467-473.

7. Julian TB, Constantino JP, Vicini FA et al. Early toxicity results with 3-D conformal external beam therapy (CEBT) from the NSABP B-39/RTOG 0413 Accelerated partial breast irradiation (APBI) trial. Int J Radiat Oncol Biol Phys 2011; 81S: S7 [abstract].

8. Skowronek J, Wawrzyniak-Hojczyk M, Ambrochowicz K. Brachytherapy in accelerated partial breast irradiation (APBI) review of treatment methods. J Contemp Brachytherapy 2012; 3: 152-164.

9. Van Dye J, Batista JJ, Bauman GS. Accuracy and Uncertainty Considerations in Modern Radiation Oncology. The Modern Technology of Radiation Oncology. Volume 3. Van Dye J (ed.). 2013; pp. 361-412.

10. Tanderup K, Kirisits C, Lindegaard JC et al. Margin concepts in image-guided brachytherapy. Comprehensive brachytherapy: physical and clinical aspects. Venselaar JLM, Baltas D, Meigooni AS et al. (eds.). 2013; pp. 235-251.

11. Hellebust TP, Krisits C, Berger D et al. Recommendations from Gynaecological (GYN) GED-ESTRO Working Group: Considerations and pitfalls in commissioning and applicator reconstruction in 3D image-based treatment planning of cervix cancer brachytherapy. Radiother Oncol 2010; 96: 153-160.

12. Kiristis C, Lang S, Dimopoulos J et al. Uncertainties when using only one MRI-based treatment plan for subsequent highdose rate tandem and ring applications in brachytherapy of cervix cancer. Radiother Oncol 2006; 81: 269-275.

13. Simnor T, Li S, Lowe G et al. Justification for interfraction correction of catheter movement in fractionated high doserate brachytherapy treatment of prostate cancer. Radiother Oncol 2009; 93: 253-258.

14. Bloom ES, Kirsner S, Mason BE et al. Accelerated partial breast irradiation using the strut-adjusted volume implant single-entry hybrid catheter in brachytherapy for breast cancer in the setting of breast augmentation. Brachytherapy 2011; 10: $178-183$.

15. Glifford KA, Pacha O, Adelaide A et al. A new paradigm for calculating skin dose. Brachytherapy 2013; 12: 114-119.

16. Gifford KA, Nelson CL, Kirsner SM et al. On the feasibility of treating to a $1.5 \mathrm{~cm}$ PTV with a commercial single-entry hybrid applicator in APBI breast brachytherapy. J Contemp Brachy 2011; 1: 29-33.

17. Skowronek J, Bieleda G, Laski P et al. Can we improve the dose distribution for a single or multi-lumen breast balloon used for Accelerated Partial Breast Irradiation? J Contemp Brachytherapy 2013; 3: 134-138.

18. Keisch M, Vicini F, Kuske RR et al. Initial clinical experiences with the MammoSite breast applicator in women with early-stage breast treated with breast-conserving therapy. Int J Radiat Oncol Biol Phys 2003; 55: 289-293.

19. Vicini F, Beitsch P, Quiet C et al. First analysis of patient demographics, technical reproducibility, cosmesis, and early toxicity: results of the American Society of Breast Surgeons MammoSite Breast Brachytherapy registry Trial. Cancer 2005; 10: 1138-1148.

20. Tokita KM, Cuttino LW, Vicini FA et al. Optimal application of the Contura multilumen balloon breast brachytherapy catheter vacuum port to deliver accelerated partial breast irradiation. Brachytherapy 2011; 10: 184-189.

21. Bhatt AD, Crew JB, Bhatt $G$ et al. Interfraction accumulation of seroma during accelerated partial breast irradiation: preliminary results of a prospective study. Brachytherapy 2012; 11: 374-379. 
22. Kim Y, Trombetta MG. Dosimetric evaluation of multilumen intracavitary balloon applicator rotation in high-dose-rate brachytherapy for breast cancer. J Appl Clin Med Phys 2014; 1: 76-89.

23. Ouhib Z, Benda R, Kasper M et al. Accurate verification of balloon rotation correction for the Contura multilumen device for accelerated partial breast irradiation. Brachytherapy 2011; 10: 325-330.

24. Dickler A, Kirk M, Choo J et al. Treatment volume and dose optimization of MammoSite breast brachytherapy applicator. Int J Radiat Oncol Biol Phys 2004; 59: 469-474.

25. Weed DW, Edmundson GK, Vicini FA et al. Accelerated partial breast irradiation: a dosimetric comparison of three different techniques. Brachytherapy 2005; 4: 121-129.

26. Shaitelman SF, Vicini FA, Grills IS et al. Differences in effective target volume between various techniques of accelerated partial breast irradiation. Int J Radiat Oncol Biol Phys 2012; 82: 30-36.

27. Perera F, Yu E, Engel J et al. Patterns of breast recurrence in a pilot study of brachytherapy confined to the lumpectomy site for early breast cancer with six years minimum follow-up. Int J Radiat Oncol Biol Phys 2003; 57: 1239-1246.

28. Chen S, Dickler A, Kirk M et al. Patterns of failure after MammoSite brachytherapy partial breast irradiation: a detailed analysis. Int J Radiat Oncol Biol Phys 2007; 69: 25-31.

29. Husain ZA, Mahmood U, Hanlon A et al. Accelerated partial breast irradiation via brachytherapy: a pattern-of-care analysis with ASTRO consensus statement groupings. Brachytherapy 2011; 10: 479-485.

30. Shah C, Wilkinson JB, Keisch $M$ et al. Impact of margin status on outcomes following accelerated partial breast irradiation using single-lumen balloon-based brachytherapy. Brachytherapy 2013; 12: 91-98.

31. Wilkinson JB, Beitsch PD, Shah C et al. Evaluation of current consensus statement recommendations for accelerated partial breast irradiation: a pooled analysis of William Beaumont Hospital and American Society of Breast Surgeon MammoSite Registry Trial Data. Int J Radiat Oncol Biol Phys 2013; 85: 1179-1185. 